\title{
The Big Five personality traits and regularity of lifetime dental visit attendance: evidence of the Survey of Health, Ageing, and Retirement in Europe (SHARE)
}

\author{
Ghazal Aarabi $^{1} \cdot$ Carolin Walther $^{1} \cdot$ Kübra Bunte $^{1} \cdot$ Kristin Spinler $^{1,2} \cdot$ Elzbieta Buczak-Stec $^{3} \cdot$ Hans-Helmut König $^{3}$. \\ André Hajek ${ }^{3}$ iD
}

Received: 2 November 2021 / Accepted: 7 December 2021 / Published online: 28 December 2021

(c) The Author(s) 2021

\begin{abstract}
Background Regular dental visits are essential for the prevention, early detection and treatment of worldwide highly prevalent oral diseases. Personality traits were previously associated with treatment compliance, medication adherence and regular doctor visits, however, the link between personality traits and regular dental visit attendance remains largely unexplored. Thus, the objective of this study is to clarify this link.

Methods Data (wave 7) of the Survey of Health, Ageing and Retirement in Europe (SHARE) were used, focusing on Germany $(n=2822)$. Personality was assessed using the 10-item Big Five Inventory (BFI-10). Regular dental visits were assessed. Multiple logistic regressions were used, adjusting for various covariates.

Results Majority of the participants (84\%) reported to attend regular dental visits during lifetime. Regularity of lifetime dental visit attendance was positively and significantly associated with increased extraversion [OR 1.13, 95\% CI (1.01-1.26)], increased conscientiousness [OR 1.26, 95\% CI (1.10-1.44)], and increased openness to experience [OR 1.12, 95\% CI (1.01-1.26)]. However, there was a lack of association with agreeableness and neuroticism. Moreover, the outcome measure was positively associated with younger age, being female, born in Germany, being married, higher education, being retired (compared to being homemaker), whereas it was not associated with obesity or chronic diseases.

Conclusions Identification of personality traits that are associated with regular dental visits can support prevention, screening and clinical management of oral diseases. Further research in this field may facilitate the development and increase the incorporation of individualized concepts to enhance patient compliance and attendance, and thus the provision of oral and dental care services.
\end{abstract}

Keywords Dental service - Dental visits - Dental care use - Dental care utilization · Oral health services · Quality of life $\cdot$ SHARE $\cdot$ Personality $\cdot$ Extraversion · Conscientiousness · Openness to experience $\cdot$ Agreeableness $\cdot$ Neuroticism · Emotional stability $\cdot$ Big Five

Ghazal Aarabi and Carolin Walther shared first.

André Hajek

a.hajek@uke.de

1 Department of Periodontics, Preventive and Restorative Dentistry, University Medical Center Hamburg-Eppendorf, Hamburg, Germany

2 Institute of Medical Sociology, Center for Psychosocial Medicine, University Medical Center Hamburg-Eppendorf, Hamburg, Germany

3 Department of Health Economics and Health Services Research, University Medical Center Hamburg-Eppendorf, Hamburg Center for Health Economics, Martinistr. 52, 20246 Hamburg, Germany

\section{Introduction}

More than half of the global population lacks essential health services [1], including oral health services. Need of appropriate oral health services is a significant matter, since 3.58 billion people of the global population were affected by oral diseases as of 2016, which include untreated dental caries, severe periodontitis and oral cancer [2]. Mostly, the disadvantaged members of the society are affected by oral diseases, where access to oral health services is often nonexistent or limited [3]. However-beyond the existing need in the majority of the global population-the dental service use still remains low even in high-income countries [4]. 
In Germany, basic dental services are part of the statutory health insurance, though out-of-pocket payments for dental prosthetics are common [5].

Socioeconomic status [6, 7], migration background [8], level of education [9] are significant determinants of dental service use and thereof oral healthcare utilization $[10,11]$. Yet, further factors that are associated with service uptake in a setting, where health services are widely available but utilization is limited, are understudied.

In this context, personality traits may be an additional important but underestimated patient-related determinant of health care utilization in the era of person-centered and evidence-based medicine [12]. Literature identified five personality characteristics that are associated with use of preventive health care use [13]: conscientious (individuals tend to be careful and/or diligent and are usually task and goaldirected), neuroticism (individuals tend to feel depressed, anxious, impulsive, and display angry hostility), openness to experience (individuals being imaginative and are open for new ideas), extraversion (individuals are sociable and outgoing), and lastly agreeableness (individuals are compliant, tend to be altruistic and warm). Yet, the association between personality factors and use of dental services remains largely unexplored [14-16].

Screening in disease prevention and treatment is one of the priorities of health promotion. So far, disease prevention and early detection is only possible, when health services are regularly used by the public.

Worldwide prevalent oral diseases are no exception, thus, the present study will investigate the association between the Big Five personality traits and regularity of lifetime dental visit attendance, while taking demographic and socioeconomic factors into consideration, in a nation-representative older adult population from Germany.

\section{Materials and methods}

\section{Sample}

A cross-sectional study was conducted on available German data from wave 7 (taking place in the year 2017) of the Survey of Health Ageing and Retirement in Europe (SHARE) [17]. We restricted our main analyses to Germany due to differences in the healthcare system between the countries. SHARE includes participants residing in private households aged 50 years and above and their spouses in various European countries and Israel. Health status, demographic, socioeconomic, and social factors are collected via computerassisted and/or paper-based surveys with personal interviews in SHARE and kept as nationally representative samples. Further details of the study and its protocol can be found in the publication by Börsch-Supan et al. from 2013 [18].
Ethical approval of SHARE from first to fourth waves was obtained from the Ethics Committee of the University of Mannheim. In 2018, the Ethics Council of the Max PlanckSociety reviewed and approved the fourth and the consecutive waves of the SHARE project. Oral consent was given by SHARE participants prior to the CAPI interview.

\section{Assessment of regular and irregular dental visits}

The primary outcome measure was the regular dental visit attendance, which was recorded as binary categorical variable. Participants were asked the following question and requested to answer with 'yes' or 'no': "Now consider your entire life. Have you ever gone to a dentist regularly for check-ups or dental care?". Participants that answered with a 'yes' were classified as regulars and with 'no' were classified as irregulars.

\section{Assessment of personality traits}

Personality factors were the main independent variables. The 10-item Big Five Inventory (BFI-10; self-rating scale) [19] was used to assess personality (in terms of agreeableness, conscientiousness, extraversion, neuroticism and openness to experience). It is an established personality inventory measuring the Big Five personality dimensions (with two items each; each dimension ranges from 1 to 5; where a higher value represents a stronger correspondent trait). Personality trait was included as the main independent variable in the regression analyses.

\section{Covariates}

In accordance with previous research [14], covariates were selected. In directed acyclic graphs (DAG) notation, our aim was to block the backdoor path (i.e., a non-causal path from $X$ to $Y$; usually common causes of $X$ and $Y$ [20]) between personality factors and regular dental visit attendance via sociodemographic and health-related factors. Age (continuous), sex (female; male), marital status (registered partnership/married and living together with spouse; married, living separated from spouse; never married; divorced; widowed), born in Germany (no; yes), employment status (retired; employed/self-employed; unemployed; permanently sick or disabled; homemaker; other), education (primary education; secondary education; tertiary education; according to the International Standard Classification of Education (ISCED)97 [21]), and obesity (body-mass-index $\geq 30 \mathrm{~kg} / \mathrm{m}^{2}$; using self-rated height and weight) were included as covariates. Moreover, a chronic conditions count (sum score from 0 to 11: high blood pressure or hypertension; high blood cholesterol; stroke or cerebral vascular disease; diabetes or high blood sugar; chronic lung disease; arthritis, including 
osteoarthritis, or rheumatism; cancer or malignant tumor; stomach or duodenal ulcer, peptic ulcer; Parkinson's disease; cataracts; hip fracture or femoral fracture) was used as covariate.

\section{Statistical analyses}

The sample characteristics are shown stratified by regular dental visits. Moreover, multiple logistic regressions were used to investigate the association between personality factors and regular dental visits. The results from the logistic regression analyses were reported as odds ratios with 95\% confidence intervals and $p$ values. The significance level was set at 0.05 . All statistical analyses were performed using Stata 16.0 (Stata Corp., College Station, Texas).

\section{Results}

\section{Descriptive statistics}

The mean age of the participants was 66.6 years (SD 9.2 years; $50-95$ years) and $52 \%$ of the participants were females in the total analytical sample. About $84 \%$ of the individuals had reported to have attended regular dental visits during lifetime. Stratified by regular dental visits, sample characteristics are shown in Table 1. Significant differences between these groups were present in age, sex, country of origin, educational level, employment status, chronic conditions, conscientiousness, extraversion, and openness to experience.

Table 1 Sample characteristics for the analytical sample (stratified by regular dental visits; $n=2822$ )

\begin{tabular}{|c|c|c|c|}
\hline & $\begin{array}{l}\text { Not regular dental visits } \\
(n=453) \\
\text { Mean }(\mathrm{SD}) / n(\%)\end{array}$ & $\begin{array}{l}\text { Regular dental visits } \\
(n=2369) \\
\text { Mean }(\mathrm{SD}) / n(\%)\end{array}$ & $p$ value \\
\hline Age (in years) & $68.8(9.7)$ & $66.2(9.0)$ & $<.001$ \\
\hline Sex & & & .001 \\
\hline Men & $273(20.2 \%)$ & $1080(79.8 \%)$ & \\
\hline Women & $180(12.3 \%)$ & $1289(87.7 \%)$ & \\
\hline Country of origin & & & $<.001$ \\
\hline Not born in country of interview & $83(24.1 \%)$ & $262(75.9 \%)$ & \\
\hline Born in country of interview & $370(14.9 \%)$ & $2107(85.1 \%)$ & \\
\hline Marital status & & & .60 \\
\hline Married, living separated from spouse; never married; divorced; widowed & $158(20.4 \%)$ & $615(79.6 \%)$ & \\
\hline Married and living together with spouse; registered partnership & $295(14.4 \%)$ & $1754(85.6 \%)$ & \\
\hline Education & & & $<.001$ \\
\hline Primary education & $98(32.6 \%)$ & $203(67.4 \%)$ & \\
\hline Secondary education & $266(16.5 \%)$ & $1351(83.5 \%)$ & \\
\hline Tertiary education & $89(9.8 \%)$ & $815(90.2 \%)$ & \\
\hline Employment status & & & $<.001$ \\
\hline Retired & $276(17.8 \%)$ & $1276(82.2 \%)$ & \\
\hline Employed/self-employed & $111(11.7 \%)$ & $839(88.3 \%)$ & \\
\hline Unemployed & $11(19.0 \%)$ & $47(81.0 \%)$ & \\
\hline Permanently sick or disabled & $17(19.5 \%)$ & $70(80.5 \%)$ & \\
\hline Homemaker & $31(20.5 \%)$ & $120(79.5 \%)$ & \\
\hline Other & $7(29.2 \%)$ & $17(70.8 \%)$ & \\
\hline Weight category & & & .21 \\
\hline Non-obese & $332(15.6 \%)$ & $1797(84.4 \%)$ & \\
\hline Obese & $121(17.5 \%)$ & $572(82.5 \%)$ & \\
\hline Chronic conditions (from 0 to 11 ) & $1.5(1.4)$ & $1.2(1.2)$ & $<.001$ \\
\hline Agreeableness (from 1 to 5 , higher values reflect higher agreeableness) & $3.4(0.9)$ & $3.4(0.8)$ & .12 \\
\hline Conscientiousness (from 1 to 5 , higher values reflect higher conscientiousness) & $4.0(0.9)$ & $4.2(0.8)$ & $<.001$ \\
\hline Extraversion (from 1 to 5, higher values reflect higher extraversion) & $3.2(1.0)$ & $3.5(1.0)$ & $<.001$ \\
\hline Neuroticism (from 1 to 5, higher values reflect higher neuroticism) & $2.6(1.0)$ & $2.6(1.0)$ & .43 \\
\hline $\begin{array}{l}\text { Openness to experience (from } 1 \text { to } 5 \text {, higher values reflect higher openness to experi- } \\
\text { ence) }\end{array}$ & $3.2(1.0)$ & $3.5(1.0)$ & $<.001$ \\
\hline
\end{tabular}


With regard to effect sizes (Cohen's $d$ ), the association between agreeableness and regular dental visits during lifetime was 0.10 (in parentheses: among all individuals included in the SHARE study: 0.12). Cohen's $d$ for the association between conscientiousness and regular dental visits during lifetime was 0.27 (0.06). Cohen's $d$ for the association between extraversion and regular dental visits during lifetime was $0.21(0.11)$. Cohen's $d$ for the association between neuroticism and regular dental visits during lifetime was $-0.06(-0.15)$. Cohen's $d$ for the association between openness to experience and regular dental visits during lifetime was $0.28(0.25)$.

\section{Association between regularity of lifetime dental visit attendance and the Big Five personality traits}

In unadjusted logistic regressions (not shown), 2915 individuals were included. After adjusting for sociodemographic factors (age, sex, marital status, born in Germany, employment status, and education), 2864 individuals were included. When obesity and a chronic conditions count were also added to regressions, 2822 individuals remained in the analytical sample.

Detailed results from multiple logistic regression analyses are given in Table 2. Regressions showed that the likelihood of regular dental visits was positively associated with increased extraversion [OR 1.13 (95\% CI 1.01-1.26)], increased conscientiousness [OR 1.26 (95\% CI 1.10-1.44)], and increased openness to experience [OR 1.12 (95\% CI 1.01-1.26). However, regular dental visit attendance was not associated with agreeableness and neuroticism. Moreover, while the outcome measure was positively associated with younger age, being female, born in Germany, being married, higher education, being retired (compared to being homemaker), it was not associated with obesity or chronic diseases.

In sensitivity analysis, rather implausible BMI values $\geq 50 \mathrm{~kg} / \mathrm{m}^{2}$ were removed. The main findings remained nearly the same in terms of significance and effect size (see Supplementary Table 1).

In further sensitivity analysis, regressions were stratified by age group (50 to 64 years; 65 to 74 years; 75 years

Table 2 Determinants of regular dental visits $(0=$ no regular dental visits, $1=$ regular dental visits $)$

\begin{tabular}{|c|c|}
\hline Independent variables & Regular dental visits \\
\hline Age & $0.98 * *(0.96-0.99)$ \\
\hline Sex: women (reference category: men) & $2.27 * * *(1.78-2.89)$ \\
\hline Country of origin: born in country of interview (reference category: not born in country of interview) & $1.60 * *(1.20-2.15)$ \\
\hline Marital status: married and living together with spouse; registered partnership (reference category: other ${ }^{\dagger}$ ) & $1.45^{* *}(1.14-1.83)$ \\
\hline Education: secondary education (reference category: primary education) & $2.19 * * *(1.62-2.98)$ \\
\hline Tertiary education & $4.40 * * *(3.04-6.37)$ \\
\hline Employment status:-Employed/self-employed (Reference category: retired) & $0.92(0.66-1.30)$ \\
\hline Unemployed & $0.88(0.41-1.87)$ \\
\hline Permanently sick or disabled & $0.88(0.47-1.66)$ \\
\hline Homemaker & $0.55^{*}(0.34-0.89)$ \\
\hline Other & $0.40^{+}(0.15-1.04)$ \\
\hline Weight category: obesity (ref.: non-obesity) & $1.03(0.80-1.32)$ \\
\hline Chronic conditions (count score) & $0.93(0.86-1.02)$ \\
\hline Agreeableness (from 1 to 5 , higher values reflect higher agreeableness) & $1.09(0.96-1.24)$ \\
\hline Conscientiousness (from 1 to 5 , higher values reflect higher conscientiousness) & $1.26^{* * *}(1.10-1.44)$ \\
\hline Extraversion (from 1 to 5 , higher values reflect higher extraversion) & $1.13^{*}(1.01-1.26)$ \\
\hline Neuroticism (from 1 to 5 , higher values reflect higher neuroticism) & $0.94(0.84-1.05)$ \\
\hline Openness to experience (from 1 to 5 , higher values reflect higher openness to experience) & $1.12 *(1.01-1.26)$ \\
\hline Constant & $36.32 * * *(1.73)$ \\
\hline Observations & 2822 \\
\hline Pseudo $R^{2}$ & 0.09 \\
\hline
\end{tabular}

Findings of multiple logistic regressions. Odds ratios were reported; 95\% CI in parentheses

$* p<0.05$

$* * p<0.01$

$* * * p<0.001$

${ }^{+} p<0.10$

†ther including: married, living separated from spouse; never married; divorced; widowed 
and over; see Supplementary Table 2). In this regression analysis, particularly conscientiousness was associated with the likelihood of regular dental visits among individuals aged 50 to 64 years [OR 1.43 (95\% CI 1.15-1.79)] and among individuals aged 75 years and over [OR 1.45 (95\% CI 1.11-1.88)].

In a last analysis, regressions were no longer restricted to Germany (see Supplementary Table 3). The likelihood of regular dental visits was positively associated with increased extraversion [OR 1.05 (95\% CI 1.03-1.07)], increased agreeableness [OR 1.12 (95\% CI 1.09-1.14)], decreased neuroticism [OR 0.91 (95\% CI 0.89-0.93)] and increased openness to experience [OR 1.14 (95\% CI 1.12-1.17) among all older Europeans.

\section{Discussion}

Using nationally representative data, our study showed that the likelihood of regular lifetime dental visit attendance was positively associated with increased extraversion, increased conscientiousness, and increased openness to experience, whereas the outcome measure was not associated with agreeableness and neuroticism. Furthermore, the outcome measure was positively associated with younger age, being female, born in Germany, being married, higher education, being retired (compared to being homemaker), whereas it was not associated with obesity or chronic diseases.

A number of studies suggest that higher scores of conscientiousness are significant predictors of better compliance in periodontal maintenance therapy [22]. Conscientious individuals tend to be more efficient and well-organized. Usually they are more task and goal-directed and the association to longtime regular dental visits appears plausible. A systematic review reported an association between extraversion and conscientiousness with increased uptake of cancer screening [23]. This is in line with our findings and it is suspected, that individuals with higher scores in extraversion are in general more sociable and energetic, thus having a more positive attitude towards their dental appointments. Lastly, different behavioral patterns might explain the lack of dental visits in neurotic individuals: dental anxiety can arise in neurotic individuals [24] and can result in maladaptive behavior.

Furthermore, previous studies suggested that personality traits might be related to treatment adherence and compliance $[25,26]$, treatment medication adherence [27, $28]$, and doctor visits in general $[29,30]$, which in certain conditions significantly reduce quality of life [29], such as in rheumatoid arthritis [31, 32], depression [33, 34], attention deficit hyperactivity disorder [35], multiple sclerosis [36], and cancer screening [23]. Oral diseases are also a significant contributor to reduced quality of life
[37]. Thus, increasing uptake of regular dental visits is important to prevent and treat oral diseases and improve quality of life.

This is the first study examining the association between personality characteristics and regular dental visits in Germany. Identification of subjective indicators that are associated with healthcare utilization may complement interventions and/or treatments to increase attendance, compliance and maintenance for individuals at risk for irregular dental visits, and thus improve oral health. Based on the results, one way to increase the attendance to regular dental visits, and thus screening and prevention for oral diseases, could be the improvement of health literacy through personalized education programs addressed to specific personality types [38]. Next to important and well-known socioeconomic and demographic factors, also personality should be considered for the patient-centered oral health care planning.

\section{Strengths and limitations}

Data were taken from the nationally representative SHARE study. The BFI-10 was used to quantify personality factors. One question with a high face validity was used to quantify the outcome measure. It should be noted that the SHARE study has a small sample selection bias [10] and longitudinal studies are required to confirm our results based on crosssectional data.

Supplementary Information The online version contains supplementary material available at https://doi.org/10.1007/s40520-021-02051-2.

Funding Open Access funding enabled and organized by Projekt DEAL. The SHARE data collection has been primarily funded by the European Commission through FP5 (QLK6-CT-2001-00360), FP6 (SHARE-I3: RII-CT-2006-062193, COMPARE: CIT5CT-2005-028857, SHARELIFE: CIT4-CT-2006-028812) and FP7 (SHARE-PREP: $\mathrm{N}^{\circ} 211909$, SHARE-LEAP: $\mathrm{N}^{\circ} 227822$, SHARE M4: $N^{\circ}$ 261982). Additional funding from the German Ministry of Education and Research, the Max Planck Society for the Advancement of Science, the U.S. National Institute on Aging (U01 AG09740-13S2, P01_AG005842, P01_AG08291, P30_AG12815, R21_AG025169, Y1-AG-4553-01, IAG_BSR06-11, OGHA_04-064, HHSN271201300071C) and from various national funding sources is gratefully acknowledged (see www.share-project.org).

\section{Declarations}

Conflict of interest On behalf of all authors, the corresponding author states that there is no conflict of interest.

Ethical approval Ethical approval of SHARE from first to fourth waves was obtained from the Ethics Committee of the University of Mannheim. In 2018, the Ethics Council of the Max Planck Society reviewed and approved the fourth and the consecutive waves of the SHARE project. 
Informed consent Informed consent was obtained from all subjects involved in the study.

Open Access This article is licensed under a Creative Commons Attribution 4.0 International License, which permits use, sharing, adaptation, distribution and reproduction in any medium or format, as long as you give appropriate credit to the original author(s) and the source, provide a link to the Creative Commons licence, and indicate if changes were made. The images or other third party material in this article are included in the article's Creative Commons licence, unless indicated otherwise in a credit line to the material. If material is not included in the article's Creative Commons licence and your intended use is not permitted by statutory regulation or exceeds the permitted use, you will need to obtain permission directly from the copyright holder. To view a copy of this licence, visit http://creativecommons.org/licenses/by/4.0/.

\section{References}

1. Nations $U$ (2020) The sustainable development goals report. 8

2. Organization, W.H. Oral Health (2021) Available from: https:// www.who.int/health-topics/oral-health/\#tab=tab_1

3. Northridge ME, Kumar A, Kaur R (2020) Disparities in access to oral health care. Annu Rev Public Health 41:513-535

4. Kandelman D et al (2012) Oral health care systems in developing and developed countries. Periodontol 2000 60:98-109

5. Bock J-O et al (2014) Inequalities in out-of-pocket payments for health care services among elderly Germans-results of a population-based cross-sectional study. Int J Equity Health 13:3

6. Machry RV et al (2013) Socioeconomic and psychosocial predictors of dental healthcare use among Brazilian preschool children. BMC Oral Health 13:60

7. Vilella KD et al (2016) The association of oral health literacy and oral health knowledge with social determinants in pregnant Brazilian women. J Community Health 41:1027-1032

8. Aarabi G et al (2018) Oral health and access to dental care-a comparison of elderly migrants and non-migrants in Germany. Ethn Health 23:703-717

9. Shetty $\mathrm{N}$ et al (2017) Association of level of education and utilization of restorative dental care among rural women in India: cross-sectional study. Indian J Dent Res 28:642-645

10. Jang $Y$ et al (2019) Factors associated with dental service use of older Korean Americans. Commun Dent Oral Epidemiol 47:340-345

11. Spinler K et al (2019) Prevalence and determinants of dental visits among older adults: findings of a nationally representative longitudinal study. BMC Health Serv Res 19:590-590

12. Friedman $B$ et al (2013) Is personality associated with health care use by older adults? Milbank Q 91:491-527

13. Nolan A, McCrory C, Moore P (2019) Personality and preventive healthcare utilisation: evidence from the Irish longitudinal study on ageing. Prev Med 120:107-112

14. Hajek A, Kretzler B, König H-H (2021) Factors associated with dental service use based on the Andersen model: a systematic review. Int J Environ Res Public Health 18:2491

15. Luzzi L, Spencer AJ (2008) Factors influencing the use of public dental services: an application of the theory of planned behaviour. BMC Health Serv Res 8:93

16. Kato $\mathrm{T}$ et al (2019) Relationship between type D personality and dropout from dental treatment in middle-aged adults. J Oral Sci 61:264-269

17. Börsch-Supan A et al (2008) First results from the survey of health, ageing and retirement in Europe (2004-2007). Starting the longitudinal dimension. Mannheim Research Institute for the Economics of Aging, Mannheim

18. Börsch-Supan A et al (2013) Data resource profile: the survey of health, ageing and retirement in Europe (SHARE). Int J Epidemiol 42:992-1001

19. Rammstedt B, John OP (2007) Measuring personality in one minute or less: a 10-item short version of the Big Five inventory in English and German. J Res Pers 41:203-212

20. VanderWeele TJ, Shpitser I (2013) On the definition of a confounder. Ann Stat 41:196

21. UNESCO (2006) International standard classification of education. ISCED 1997. UNESCO, Paris (Re-edition ed)

22. Costa FO et al (2011) Oral impact on daily performance, personality traits, and compliance in periodontal maintenance therapy. $\mathrm{J}$ Periodontol 82:1146-1154

23. Hajek A, Kretzler B, König HH (2020) Personality and the use of cancer screenings. A systematic review. PLoS ONE 15:e0244655

24. Appukuttan DP (2016) Strategies to manage patients with dental anxiety and dental phobia: literature review. Clin Cosmet Investig Dent 8:35-50

25. Pappa $\mathrm{C}$ et al (2006) Psychiatric manifestations and personality traits associated with compliance with glaucoma treatment. J Psychosom Res 61:609-617

26. Shah $\mathrm{R}$ et al (2017) Influence of various factors on patient compliance after periodontal therapy: a pilot study. J Indian Soc Periodontol 21:50-54

27 Hazrati-Meimaneh Z et al (2020) The impact of personality traits on medication adherence and self-care in patients with type 2 diabetes mellitus: the moderating role of gender and age. J Psychosom Res 136:110178

28. Wouters $\mathrm{H}$ et al (2016) Associations between personality traits and adherence to antidepressants assessed through self-report, electronic monitoring, and pharmacy dispensing data: a pilot study. J Clin Psychopharmacol 36:465-471

29. Fenton JJ et al (2019) Patient characteristics associated with making requests during primary care visits. J Am Board Fam Med 32:201-208

30. Kannan VD, Veazie PJ (2014) Predictors of avoiding medical care and reasons for avoidance behavior. Med Care 52:336-345

31. Ko KM et al (2020) Contribution of personality traits, psychological factors, and health-related quality of life to medication adherence in patients with rheumatoid arthritis. Yonsei Med J 61:406-415

32. Donisan T et al (2017) The relationship between disease activity, quality of life, and personality types in rheumatoid arthritis and ankylosing spondylitis patients. Clin Rheumatol 36:1511-1519

33. Kruisdijk F et al (2020) Personality traits as predictors of exercise treatment adherence in major depressive disorder: lessons from a randomised clinical trial. Int J Psychiatry Clin Pract 24:380-386

34. Sadeq NA, Molinari V (2018) Personality and its relationship to depression and cognition in older adults: implications for practice. Clin Gerontol 41:385-398

35. Emilsson $\mathrm{M}$ et al (2020) Impact of personality on adherence to and beliefs about ADHD medication, and perceptions of ADHD in adolescents. BMC Psychiatry 20:139

36. Bruce JM et al (2010) Treatment adherence in multiple sclerosis: association with emotional status, personality, and cognition. $\mathbf{J}$ Behav Med 33:219-227

37. Kassebaum NJ et al (2017) Global, regional, and national prevalence, incidence, and disability-adjusted life years for oral conditions for 195 countries, 1990-2015: a systematic analysis for the global burden of diseases, injuries, and risk factors. J Dent Res 96:380-387

38. Khwankong S, Sriplung H, Kerdpon D (2018) knowledge and health belief attitudes of oral cancer and its screening among atrisk Southern Thai Muslims. J Cancer Educ 33:615-621 
Publisher's Note Springer Nature remains neutral with regard to jurisdictional claims in published maps and institutional affiliations. 